\title{
Computational Aeroacoustic Investigation of Airfoil Cascades
}

\author{
Bálint Lendvai ${ }^{1 *}$, Tamás Benedek ${ }^{1}$ \\ 1 Department of Fluid Mechanics, Faculty of Mechanical Engineering, Budapest University of Technology and Economics, \\ H-1111 Budapest, 4-6 Bertalan Lajos street, Hungary \\ * Corresponding author, e-mail: balint.Ind@gmail.com
}

Received: 24 January 2020, Accepted: 21 July 2020, Published online: 22 September 2020

\begin{abstract}
At moderate Reynolds numbers and angles of attack, the Laminar Boundary Layer (LBL) becomes unstable on the surface of airfoils, and causes periodic vortex shedding, which means undesired tonal peaks in the spectrum of the emitted aeroacoustic noise along with increased vibration and decreased aerodynamic performance. In the past, numerous research campaigns focused on the LBL vortex shedding, including measurements and numerical simulations as well. The results of these investigation showed that, the formation of the LBL instability related to the presence of the laminar separation bubble. It was also shown that, the spectrum of the emitted noise has a multitonal behavior, and the scaling of the mean frequency with the free stream velocity has a ladder structure. Based on these results, the LBL instability is a complex phenomenon; however, in the preliminary design of axial flow turbomachines the prediction of the frequency of the vortex shedding is essential, therefore the use of semi-empirical formulas is usual to achieve this goal. The previous researches mostly focused on separated airfoils, however, in case of turbomachines, the blades form a cascade, which can significantly affect the aerodynamic of the airfoils, i.e. it can affect the behavior of the LBL instability as well. According to this, in the present paper the LBL instability of NACA 0012 cascades are investigated, using 2D computational fluid mechanics and aeroacoustics simulations. The investigation involves the variation of the angle of attack, the chord based Reynolds-number and the spacing. The results are compared to the semi-empirical Brooks-Pope-Marcolini model.
\end{abstract}

\section{Keywords}

airfoil cascade, Brooks-Pope-Marcolini model, Ffowcs-Williams and Hawkings model, Laminar Boundary Layer instability, noise

\section{Introduction and objectives}

Periodic Vortex Shedding (VS) in flow past solid bodies has a great importance in case of turbomachinery and other areas of fluid mechanics [1-3] as well. In case of axial flow fans, a significant part of the noise emitted is aerodynamically generated, and originates from noise sources associated to the fan blades [4], and one of the strongest of these noise sources is the periodic VS from the fan blade surface.

In most of the cases the VS has a dominant frequency, which cause a tonal noise and the vibrations of the fan blades due the alternating pressure distribution on the blade surface. In [5] an axial fan was investigated, and the authors experienced not just the decrease of the emitted noise with the elimination of VS, but $3 \%$ increase in the performance of the machine. These results suggest that, the VS has a negative effect on the operation of the fan, additionally to the increased noise and vibrations. Avoiding these harmful phenomena, many research focused on the VS of airfoils. In [6] two types of VS are distinguished. The first one is induced by the separation behind the blunt trailing edge of the airfoil. The second one is the so called Laminar Boundary Layer (LBL) VS. This type of VS appears in a moderate chord based Reynolds number $\left(\mathrm{Re}_{C}\right)$ and Angle of Attack (AoA) range, where the Laminar Boundary Layer developing on the surface of the airfoil becomes unstable before the transition point. The transient instabilities amplify each other, and cause the roll up of the LBL. The rolled up LBL travels toward the trailing edge, and a new disturbance starts to develop (like in the case of the Tollmien-Slichting waves), and cause a periodic VS. The blades of the small-scale axial fans and unmanned aerial vehicles operate in the critical $\mathrm{Re}_{C}$ range, therefore nowadays the LBL VS has an increased interest.

Based on [7], the LBL VS is linked to the presence of the separation and reattachment of the LBL (i.e. the formation of Laminar Separation Bubble-LSB). The LSB and VS can appear on the suction and pressure side of the blades as well. The formation of the LSB is influenced by both $\operatorname{Re}_{C}$ and 
angle of attack (AoA), but the AoA has a stronger effect [8]. In [9], it was shown that, in case of lower $\operatorname{Re}_{C}$ the LBL VS is dominated by the suction side, and in case of higher $\operatorname{Re}_{C}$ the LBL VS is dominated by the pressure side, and in the intermediate region the interaction of the two boundary layers is common. However, this overlapping region becomes smaller with the increase of AoA [8]. The explanation of this phenomenon is that, the LSB moves upstream and its length decreases with the increase of $\mathrm{Re}_{C}$ on both side of the airfoil, however AoA has opposite effect on the two side: the pressure side reattachment point goes downstream and suction side reattachment point goes upstream with the increase of AoA. [8, 10, 11]. The amplitude of the pressure disturbance caused by the instability is also effected by AoA and $\operatorname{Re}_{C}$. In [11] it was shown, the disturbance growth rate in LSB increased with the increase of AoA and $\operatorname{Re}_{C}$. In [12] it was presented, in case of near stall AoA, the separation and the reattachment is alternating, which cause the decrease and the increase of the amplitudes of pressure fluctuation caused by LBL VS.

In the spectrum of the noise generated by the LBL VS multiple tonal peaks were found in [13]. In this paper it was also shown, the frequency scaling of the LBL VS by the freestream velocity $(U)$ has a ladder structure: the main frequency of the VS noise in a level is scaled by $\sim U^{0.8}$, and jump between two levels is scaled by $\sim U^{1.5}$, and the levels are overlapping. The explanation of the ladder structure can be found in $[14,15]$. It was shown, that the frequency of the developing instabilities is scaled by $\sim U^{1.5}$, causing a broadband hump in the spectrum, from which some tonal peaks exceed because of the acoustic feedback. The frequency of these tonal peaks is scaled by $\sim U^{0.8}$. The effect of the acoustic feedback on the pressure fluctuations in the LSB was also reported in [9], but the results in [16] showed that, the acoustic feedback is not necessary in the formation of the LBL VS. Additionally, in [14] it was shown, if the separation is too far from the trailing edge, the LBL VS do not generate tonal peaks in the acoustic spectrum. In [17] a NACA 0018 airfoil was investigated, and the results showed that, below $\operatorname{Re}_{C}=70000$ (when the separated LBL fails to reattach) the $f_{V S}\left(\operatorname{Re}_{C}\right)$ curve has 10 times lower slope, than in case $\operatorname{Re}_{C}=100000$. Based on the above, the LBL VS is a complicated phenomenon, however, in the literature some semi-empirical formulas $[6,18,19]$ can be found to predict the frequency of the LBL VS, which formulas are useful in the preliminary design of axial flow fans.
The above mentioned publications are based on measurement results, however CFD simulation can also be used to investigate the phenomena. The turbulence models: $k-k l-\omega$ [20] and transition SST [21] are capable of modelling the transition of LBL to TBL. In [22] the transition SST turbulence model was used in the 2D simulations of flow over a NACA 0012 airfoil. The authors showed that, the used turbulence model can predict the instability of the LBL. The results were compared to the BPM model and showed a good agreement from the view point of the VS frequency. Based on the results, the transition SST turbulence model also can simulate the multitonal nature of the LBL VS. In [23] scale adaptive simulation and the SST $k$ - $\omega$ was used in 3D simulation of a NACA-4421 airfoil. The simulated flow field was similar to measurements results, and the error of the predicted VS frequency was $14 \%$.

In the above cited papers mostly separated airfoils were investigated in 2D flow. The assumption of the 2D flow is common in the preliminary design of axial flow fans, however, the cascade effects on the aerodynamic of the blades cannot be neglected if the spacing is below 1 [4]. This suggests that, the cascade has an effect on the formation of the LBL VS as well. In the present paper we are going to investigate the self-noise mechanisms of 2D airfoil cascades of the symmetric, well-documented NACA-0012 airfoil, and compare the results of the semi-empirical and the simulation based noise estimations, focusing on the LBL VS noise. For the simulations we considered the transition SST and transition $k-k l-\omega$ turbulence models, also the spacing of the blades was set to half-, one- one and a half- and infinite chord lengths. During the simulations the chord based Reynolds number varied from $5 \cdot 10^{4}$ to $2 \cdot 10^{5}$, the angle of attack ranged from 0 to 6 degrees.

\section{Methodology}

There are multiple ways to compute numerical aeroacoustics. One potential option is the direct numerical simulation of the problem, which resolves the acoustic phenomenon both spatially and temporally. This method is constrained by the high computational power and time required for the simulation. On the other hand, the hybrid method uses Lighthill's acoustic analogy for interpreting the flow field calculated by transient (URANS, LES, etc.) simulation as sound sources, then the acoustic wave equation is used for computing sound propagation. For this reason, the method requires only a precisely described transient flow field around the sound source, which is the airfoil in our case. 
The farfield of the simulation can be covered with a low resolution mesh for the reduction of computation time. The drawback of the hybrid method is its inability to solve two-way coupled acoustic-fluid mechanics simulations. However, hybrid method is applied for its relatively low computational power requirements.

As the hybrid acoustic method, the Ffowcs-Williams and Hawkings model (FW-H) [24] is implemented in ANSYS Fluent. The FW-H acoustic model extends Lighthill's acoustic analogy by the addition of solid surface sound sources. The acoustic pressure is calculated as the sum of all surface mono- and dipole sources; also, the highest attainable frequency with a given mesh is proportional to the mesh size. For these reasons, highly resolved sound source surfaces are desirable on the shells of the investigated airfoil. A drawback of this method in ANSYS FLUENT is that, it is impossible to set acoustically reversible surfaces for the investigation of echoes, all surfaces in the flow field are transparent

The realized semi-empirical BPM model [6] predicts the third-octave selfnoise spectrum of a separated NACA-0012 based on easily measurable flow parameters. The model includes five major selfnoise mechanism:

- turbulent boundary layer trailing edge noise,

- LBL VS noise,

- blunt trailing edge VS noise,

- stall noise,

- and tip vortex formation noise.

Due to the 2D, sharp trailing edge model the tip vortex formation and blunt trailing edge noise sources were excluded from the investigation. The BPM model approximates each source term with a shape function, which amplitude and peak frequency depends on the input parameters, these shape functions can be added together for the whole emitted sound spectrum.

The input parameters include boundary layer thickness and boundary layer displacement thickness on both pressure and suction side at the trailing edge of the airfoil. The authors of BPM model also set up algebraic equations for the calculation of these parameters based on hot wire anemometer measurements. For our investigation we relied on these calculated parameters, because the resulting predicted spectra showed much better agreement with the numerically computed acoustic spectra, than the ones calculated with parameters retrieved from simulation data.

The BPM model even offers Mach number scaling and directivity correction, however, these only effect the SPL levels of the resulting spectra, therefore, these were not applied, since the current investigation focuses on the appearance and the nature of the LBL VS.

\section{Simulation setup}

The numerical grid for the two-dimensional airfoil was made in ICEM CFD meshing software. Structured mesh is required for the hybrid acoustic method, due to the high resolution grid near the airfoil and the low resolution grid far field in order to reduce computation time (Fig. 1). The farfield region was formed with a $\mathrm{C}$-grid, in the center of which was placed an $\mathrm{O}$-grid for the near field high resolution region. The mesh consisted of 210 to 290 thousand hexa elements depending on spacing. The near field mesh consisting of 80 thousand elements was kept for all spacings.

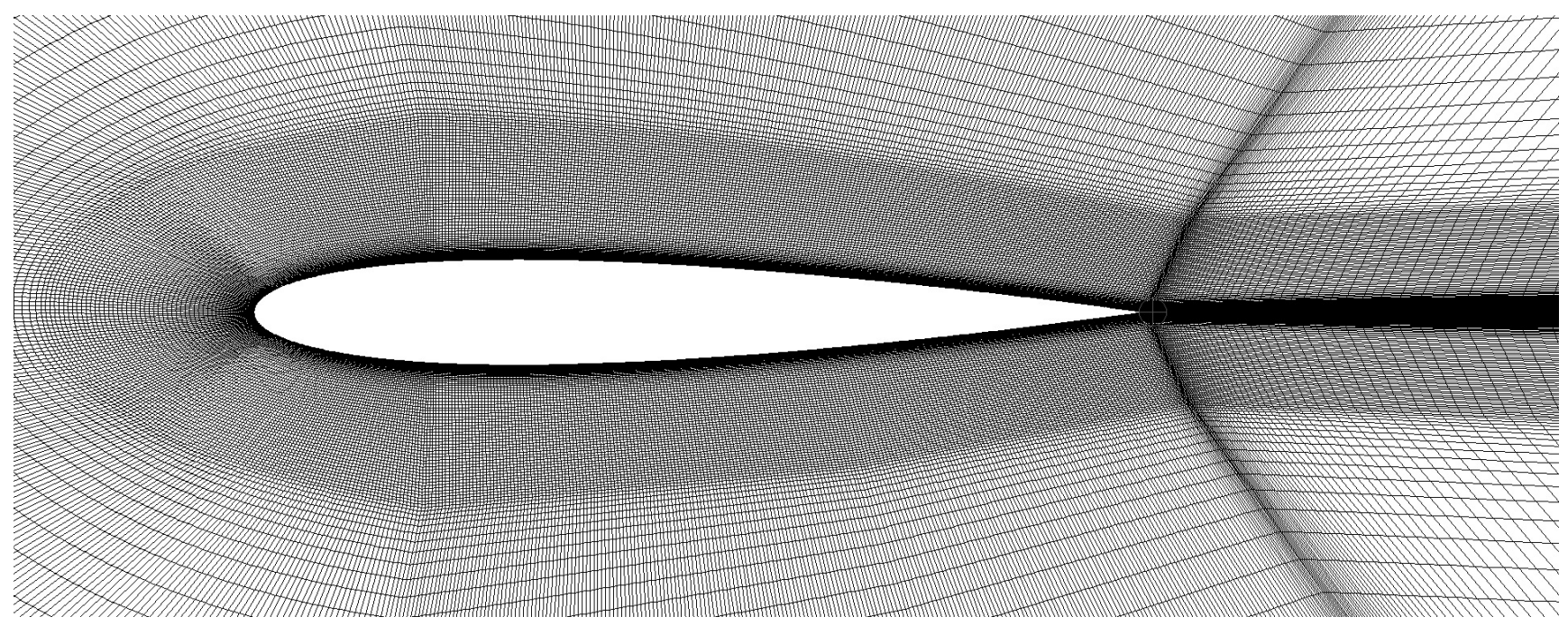

Fig. 1 Structured mesh around the airfoil 
The length of the modelled space was 40 chord length, the width was determined by the spacing of the blades. In case of infinite spacing a square field was used.

The precise pressure distribution along the surface of the noise source is essential for the Ffowcs-Williams model, therefore the surface of the airfoil was meshed with over 500 elements. The dimensionless wall distance $\left(y^{+}\right)$was kept under 1 on the surface of the airfoil for proper boundary layer computation. Mesh sensitivity analysis was carried out on a mesh generated by halving all element edges. The analysis extended to the examination of the lift and drag forces, the error of the coarser mesh was below $1 \%$.

The above mentioned transitional shear stress transport or transitional $k-k l-\omega$ turbulence model completed the pressure based URANS simulation. Our initial investigation was focused on the SST turbulence model, therefore simulations were carried out at three different chord based Reynolds numbers, however, the results were consistent throughout this range of Reynolds numbers. For this reason we chose to carry out simulations only at the lowest and highest Reynolds numbers for the $k-k l-\omega$ model. The pressure velocity coupling was set to "coupled" scheme, the spatial discretization method was "PRESTO!" and all other numerical schemes were set to be second order upwind. The boundary conditions were set to be "wall" on the surface of the airfoil, "velocity inlet" on the inlet surface, "pressure outlet" on the outlet surface and "periodic" on the parallel sides. Uniform inlet turbulence was set to be $0.05 \%$, the length scale was 0.5 meter.

The simulations were initiated with a steady state solution, after its convergence, the transient solver was turned on with a timestep of $10^{-5}$ second. After the initial transient flow settled the acoustic solver was turned on as well. The acoustic sampling was done for 0.1 second with $50 \mathrm{kHz}$ sampling frequency. Through Fast Fourier Transformation the obtainable range of spectral frequency resolution was 20 to $25 \mathrm{kHz}$ with this temporal resolution of the acoustic data.

\section{Evaluation}

For the evaluation of the simulations the pressure fields and the acoustic spectra radiated from the airfoil were investigated. The results are summarized in the tables of the Appendix (Tables 1 to 3). The examination of the pressure filed determines the origin of the instability waves, if they occur at all. Also, the development of separation can be established. In Figs. 2 to 4 representative pressure fields around the airfoil are depicted. Fig. 2 shows how the instability originating point moves towards the leading edge on the suction side as the AoA is increasing. On the pressure side, the opposite effect can be observed, which is in accordance with the literature. For the cascade effect, Fig. 3 shows how the pressure of the neighboring airfoils affect the flow pattern. In Fig. 4 we can observe a case for the simultaneous formation of separation and instability wave, for this phenomenon the acoustic spectrum must be analyzed to determine the dominating noise mechanism.

For most of the cases determining the peak frequency in the acoustic spectra was straightforward (Fig. 5). Nonetheless, for multiple cases the spectra, in accordance with literature has a multitonal behavior (Fig. 6), making the exact frequency of vortex shedding uncertain.

Tables 1 to 3 contain the results of all simulations considering the peak frequency, flow pattern and the BPM model estimation for each case as well. The spectra calculated from the BPM model are in third-octave format, meaning at higher frequencies the resolution is not adequate for determining peak frequencies with high certainty.

When comparing the BPM estimation to the simulation results with respect to whether instability in the boundary layer develops or not we can see that the numerical simulations predicts rather well the occurrence of instability. However, the BPM model always considers profile vortex shedding noise, changing only its magnitude and peak frequency according to input parameters, therefore it is not clearly distinguishable in some cases.

Apart from the proper portrayal of the instability wave, the numerical simulations predicted stall at the same cases as the semi-empirical estimation model. However in some simulations separation and instability wave appeared as well. Nonetheless, according to [14] the absence of Laminar Boundary Layer instability noise in the estimation spectrum does not necessarily mean that instability does not appear. As a result of this, the existence of instability waves cannot be determined solely on the shape of the spectrum, further investigation is required.

Although, the prediction based on numerical simulation was correct about the appearance of instability waves for most of the investigated cases, the frequency of the vortex shedding, measured by the peak frequency of the acoustic spectra was inconsistent with the BPM model in multiple cases. This can be due to either the deficiency of the applied turbulence model or the inaccuracy of the semi-empirical prediction, owing to improper boundary layer treatment or turbulence description.

The two investigated turbulence models have similar result for most of the simulated cases, the main difference in their capabilities was demonstrated at high 


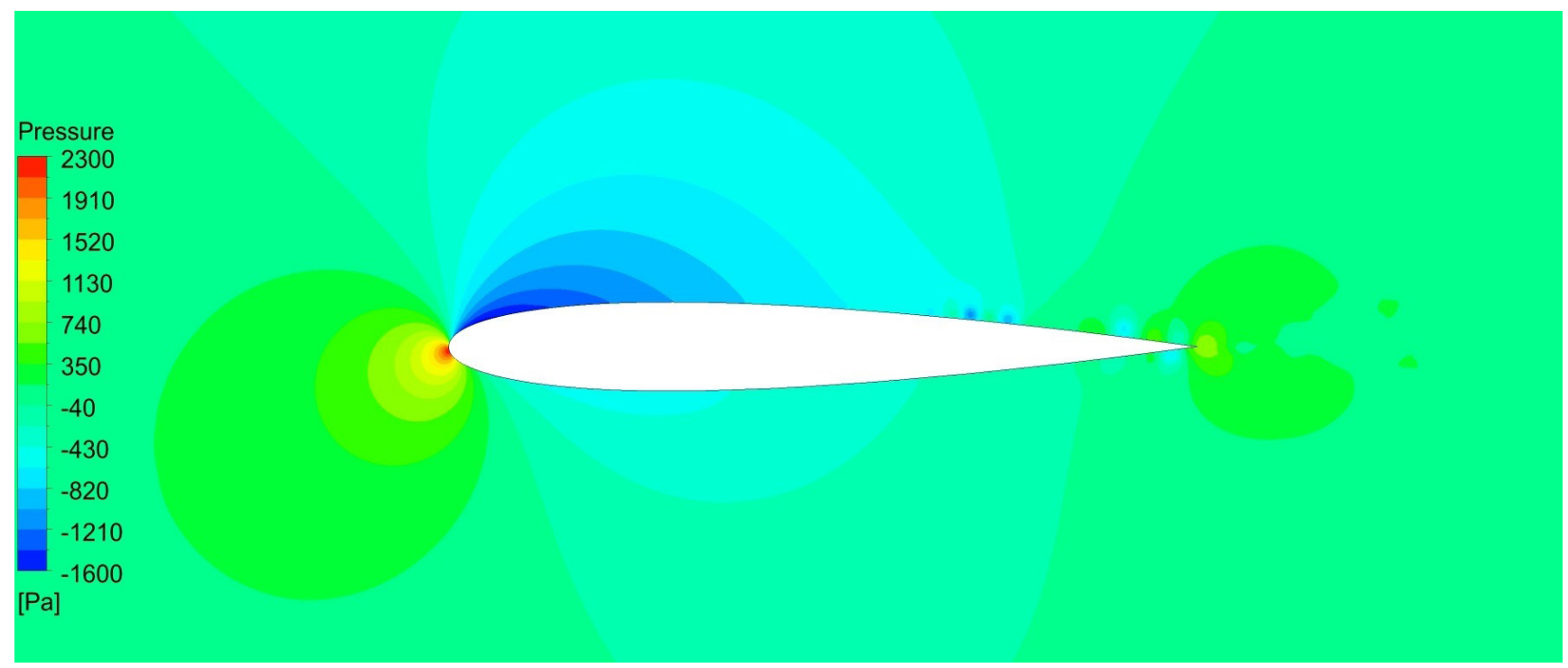

Fig. 2 Asymmetric boundary layer instability in the pressure distribution $s / c=$ infinite, $\operatorname{Re}_{C}=200000, \mathrm{AoA}=2^{\circ}, k-k l-\omega$

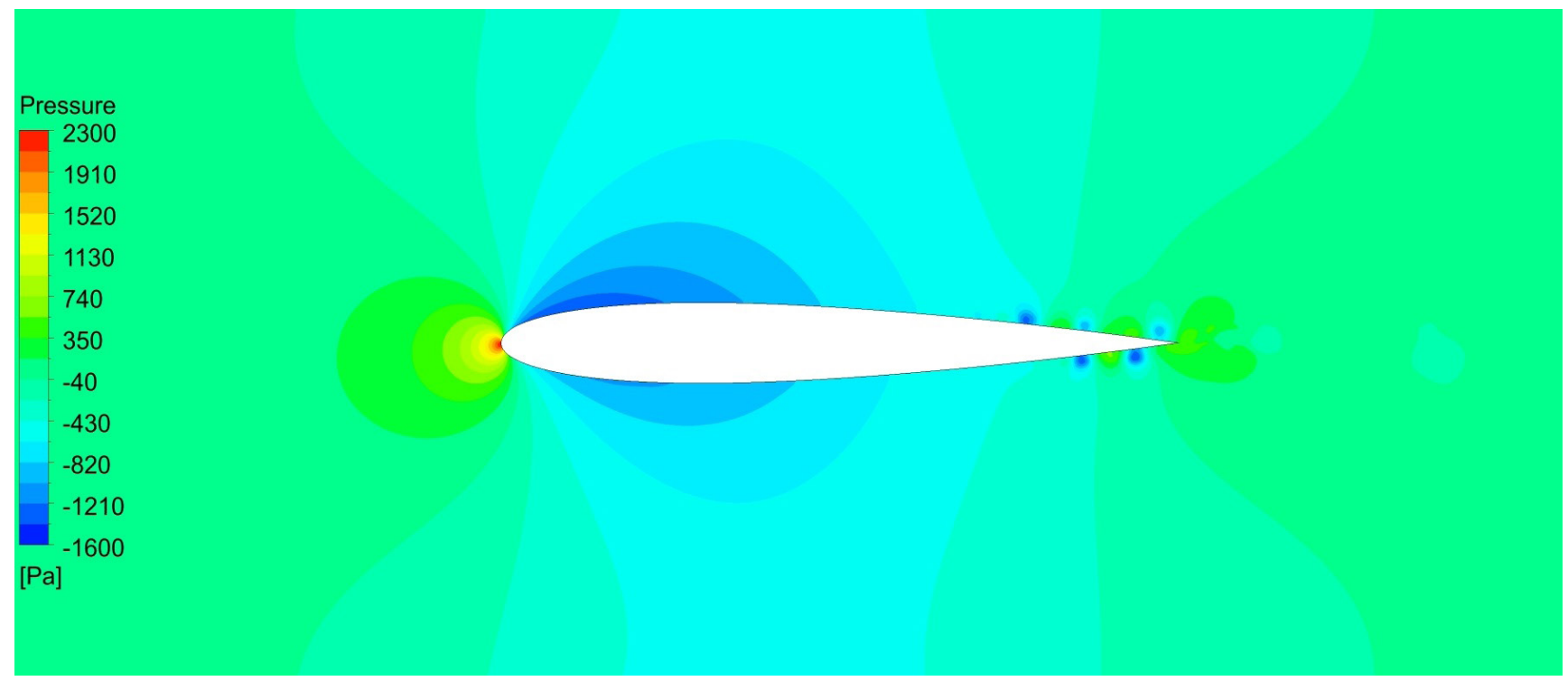

Fig. 3 Pressure distribution affected by the neighboring airfoils $s / c=1, \operatorname{Re}_{C}=200000, \mathrm{AoA}=2^{\circ}, k-k l-\omega$

Reynolds number with small spacing, where due to high velocity values the transition in the boundary layer happens rather further upstream on the airfoil. Based on the acoustical results the transition SST turbulence model handled the transition properly, however the $k-k l-\omega$ model could not resolve the problem resulting in the inability to accurately predict the occurrence of instability and therefore results in noisy, broadband acoustic spectra (Fig. 7).

For the single airfoil at low $\mathrm{Re}_{C}$ and zero AoA, an interesting phenomenon was experienced with both turbulence models. The static pressure distribution is smooth except for a small pressure jump at the trailing edge, it shows no instability in the boundary layer, however, in the wake of the airfoil some fluctuation appears in the form of vortices flowing downstream. Also, the acoustic spectra show a single $100 \mathrm{~dB}$ SPL peak around one $\mathrm{kHz}$. Because of this, we may assume that the instability would develop just in the immediate vicinity of the trailing edge. Based on this, we can say that at zero AoA the critical Reynolds number at which the boundary layer instability appears is 50000 for a single airfoil. Furthermore, we know, that at 2 degrees of AoA the instability does appear, meaning that the critical Reynolds number decreases with increasing AoA.

The effect of increasing the AoA resulted in a slight decrease in peak frequency for transition SST turbulence model at the smallest spacing, however, it had no 


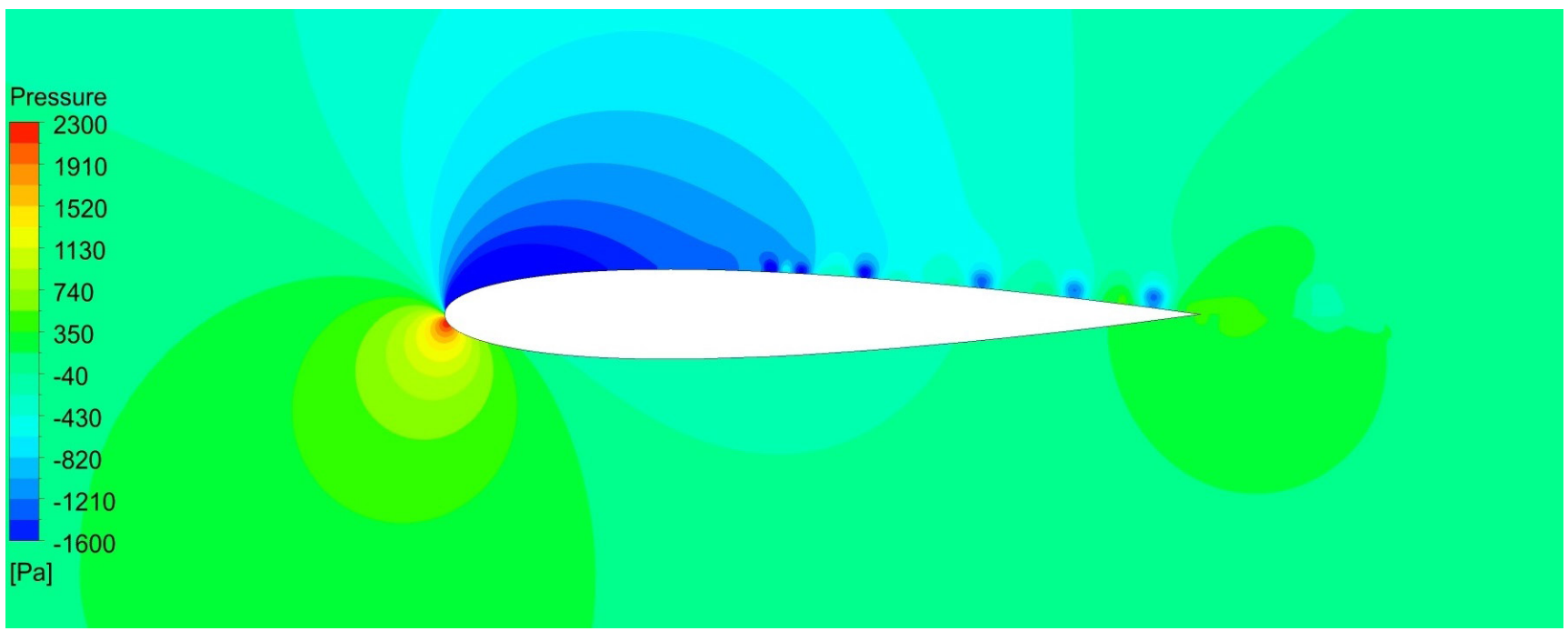

Fig. 4 Separation and instability in the pressure distribution $s / c=$ infinite, $\operatorname{Re}_{C}=200000, \mathrm{AoA}=4^{\circ}, \mathrm{SST}$

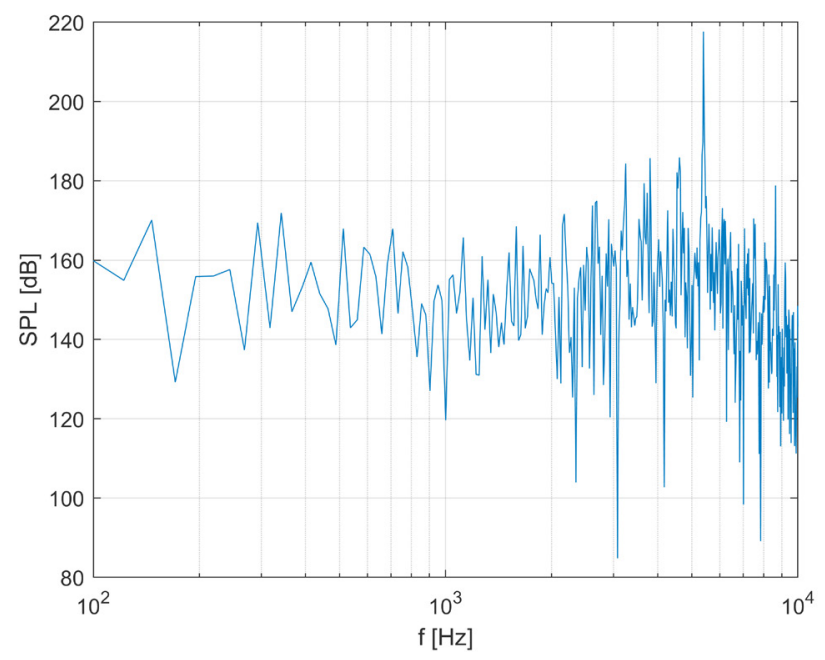

Fig. 5 Easily determinable peak frequency of the acoustic spectrum $s / c=$ infinite, $\operatorname{Re}_{C}=200000, \mathrm{AoA}=2^{\circ}, k-k l-\omega$

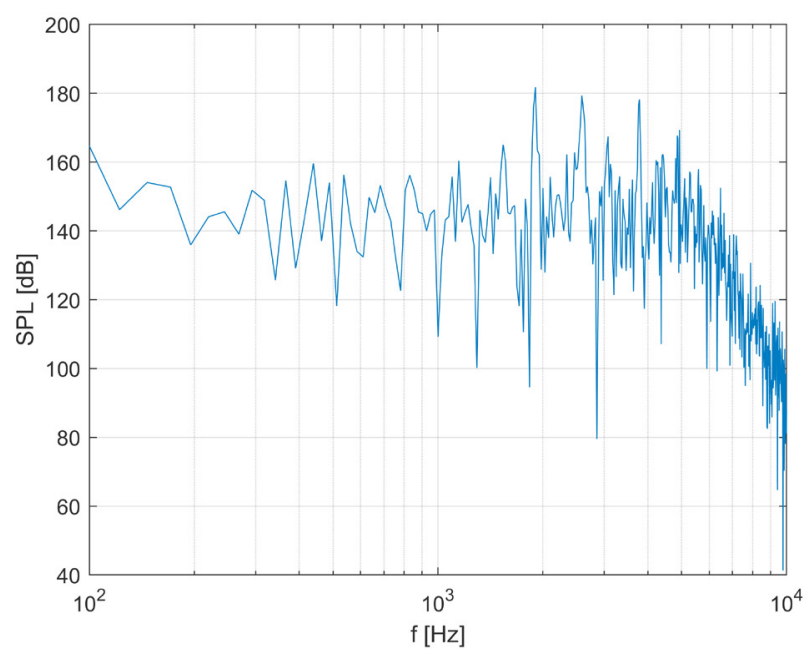

Fig. 6 Multitonal acoustic spectrum $s / c=$ infinite, $\operatorname{Re}_{C}=125000, \mathrm{AoA}=2^{\circ}, \mathrm{SST}$

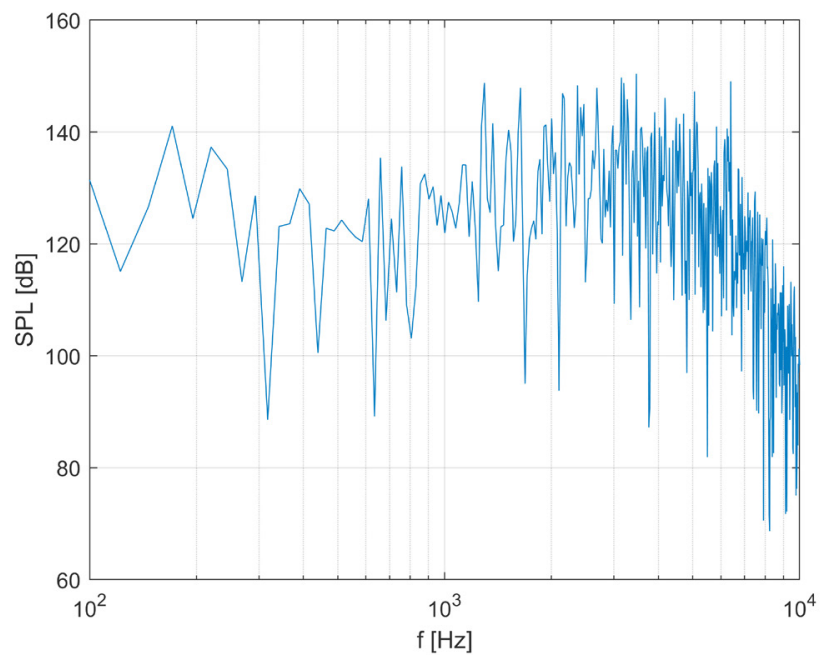

Fig. 7 Broadband selfnoise spectra of the airfoil $s / c=0.5, \operatorname{Re}_{C}=200000, \mathrm{AoA}=4^{\circ}, k-k l-\omega$

significant effect in any other examined case. The characteristic of the peak frequency does not change much when moving from infinite spacing to 1 , which is verified by [4], which states that above spacing 1 the airfoil can be considered as a separated wing. However, at cases with spacing 0.5 , the aerodynamics is heavily influenced by the cascade. The simulations of the lowest investigated spacing using the SST turbulence model showed that, the peak frequency decreased somewhat at low Reynolds number and decreased significantly at high Reynolds number, but a consistent peak was observable in all cases. On the other hand, the simulations supplemented with $k-k l-\omega$ turbulence model considerably increased the peak frequency at lower Reynolds number and failed to predict any instability noise at the investigated higher upstream velocity. 
In cases with spacing value of 1 and low Reynolds number higher harmonic components of the main peak frequency of vortex shedding appear in the acoustic spectra for all simulation results, this can be seen on Fig. 8. So far we have not found the reason for this phenomenon, due to the fact, that it was registered only with these exact parameters.

For some cases surface pressure measurement was carried out at 5-5 points on the pressure and suction side. The temporally well-resolved data was Fast Fourier Transformed for acoustic examination. Since the utilized FW-H model calculates acoustic sources on wall surfaces, the resulting spectra matched the acoustic data in the frequency domain. Similar investigation was done with point probes placed in the wake of the airfoil, with similar results.

Integral boundary layer parameters were extracted at $99 \%$ chord length. From the temporally averaged velocity field the boundary layer and momentum thickness values were calculated. These results did not correlate to the empirically based calculation established in the BPM model for boundary layer parameters in some cases. Considering the parameter sensitivity of BPM model these deviations result in completely different spectra. For this reason for the input parameters of the BPM model we calculated the boundary layer parameters utilizing the model described in BPM. The unsteady analysis of the boundary layer showed that the characteristic frequency measured in the boundary layer parameters corresponds to the frequency of the boundary layer instability and vortex shedding.

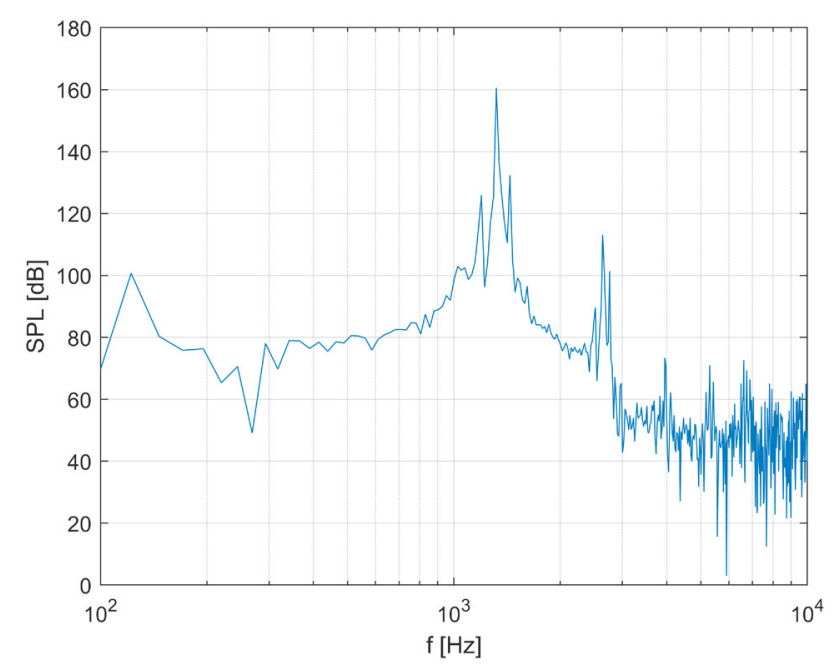

Fig. 8 Higher harmonics appear in the acoustic spectra $s / c=1, \operatorname{Re}_{C}=50000, \mathrm{AoA}=0^{\circ}, \mathrm{SST}$

\section{Conclusion}

In the present paper the vortex shedding due to the Laminar Boundary Layer instability was investigated in case of NACA-0012 airfoil cascades using 2D CFD simulations. In the simulations the transition SST and the $k-k l-\omega$ turbulence models were used. The variated parameters were the chord based Reynolds number $\left(\operatorname{Re}_{C}=50000,125000,200000\right)$, the angle of attack $\left(\mathrm{AoA}=0^{\circ}, 2^{\circ}, 4^{\circ}, 5.4^{\circ}\right)$ and the spacing $(s / c=$ infinite, $1.5,1,0.5)$. The resulted flow fields and the emitted noise calculated by the Ffowcs-Williams and Hawkings approach were investigated. The acoustic spectra were compared to semi-empirical BPM model. The following results were experienced:

- Compared to the BPM model, in case of a single airfoil, both turbulence models can handle the formation of Laminar Boundary Layer vortex shedding. The behavior of the instability is in accordance with the literature, however the main frequency of the vortex shedding was not met with predicted frequency based on the BPM model.

- For a single airfoil, $\operatorname{Re}_{C}=50000$ was found as critical value in case of $\mathrm{AoA}=0^{\circ}$, where the vortex shedding appears. This critical value is decreasing with increase of AoA.

- In accordance with the literature, the cascade has an effect on the aerodynamics of the airfoil below relative spacing of 1 . Based on the present results, the cascade affects the vortex shedding behavior of the airfoil below spacing of 1 as well.

- At the lowest investigated spacing, the transition SST turbulence model could handle the Laminar Boundary Layer instability, but the $k-k l-\omega$ model failed from this point of view.

\section{Acknowledgement}

This work has been supported by the Hungarian National Research, Development and Innovation Fund under contract NKFI K 129023.

The research reported in this paper was supported by the Higher Education Excellence Program of the Ministry of Human Capacities in the frame of Water science 1 $\&$ Disaster Prevention research area of Budapest University of Technology and Economics (BME FIKP-V $\backslash^{\prime}\{I\} Z$ ).

The research reported in this paper has been supported by the National Research, Development and Innovation Fund (TUDFO/51757/2019-ITM, Thematic Excellence Program). 


\begin{tabular}{lll}
\multicolumn{2}{l}{ Nomenclature } \\
$\mathrm{AoA}$ & {$\left[{ }^{\circ}\right]$} & Angle of Attack \\
$c$ & {$[\mathrm{~m}]$} & chord length \\
$f$ & {$[\mathrm{~Hz}]$} & frequency \\
$s$ & {$[\mathrm{~m}]$} & spacing \\
$\mathrm{Re}_{c}$ & {$[-]$} & chord based Reynolds-number \\
$U$ & {$[\mathrm{~m} / \mathrm{s}]$} & free stream velocity \\
BPM & & Brooks-Pope-Marcolini \\
FW-H & & Ffowcs-Williams and Hawkings \\
LBL & & Laminar Boundary Layer \\
LES & & Large Eddy Simulation \\
LSB & & Laminar Separation Bubble \\
SPL & {$[\mathrm{dB}]$} & Sound Pressure Level \\
URANS & & unsteady Reynolds-averaged Navier-Stokes equations \\
VS & & vortex shedding \\
2D & & two dimensional
\end{tabular}

\section{References}

[1] Hegedűs, F., Rákos, R., Kullmann, L. "Experimental and numerical study on cavitating vortex shedding behind a square cylinder", Periodica Polytechnica Mechanical Engineering, 53(2), pp. 55-60, 2009. https://doi.org/10.3311/pp.me.2009-2.01

[2] Fenyvesi, B., Horváth, Cs. "Investigation on the Nonconstant Behavior of a Vortex Flow Meter with Narrow Gauge Pipe via Conducting Measurements and Numerical Simulations", Periodica Polytechnica Mechanical Engineering, 61(3), pp. 247-254, 2017. https://doi.org/10.3311/PPme.10816

[3] Guemou, B., Seddini, A., Ghenim, A. N. "Scour around Bridge Piers: Numerical Investigations of the Longitudinal Biconcave Pier Shape", Periodica Polytechnica Mechanical Engineering, 62(4), pp. 298-304, 2018.

https://doi.org/10.3311/PPme.12263

[4] Carolus, T. "Ventilatoren /Fans/", Teubner Verlag, Wiesbaden, Germany, 2003.

[5] Longhouse, R. E. "Vortex shedding noise of low tip speed, axial flow fans", Journal of Sound and Vibration, 53(1), pp. 25-46, 1977. https://doi.org/10.1016/0022-460X(77)90092-X

[6] Brooks, T. F., Pope, D. S., Marcolini, M. A. "Airfoil Self-Noise and Prediction", NASA Reference Publication 1218, NASA Langley Research Center, Hampton, VA, USA, Rep. NASA RP-1218, 1989.

[7] Yarusevych, S., Sullivan, P. E., Kawall, J. G. "On vortex shedding from an airfoil in low-Reynolds-number flows", Journal of Fluid Mechanics, 632, pp. 245-271, 2009. https://doi.org/10.1017/S0022112009007058

[8] Pröbsting, S., Scarano F., Morris, S. C. "Regimes of tonal noise on an airfoil at moderate Reynolds number", Journal of Fluid Mechanics, 780, pp. 407-438, 2015. https://doi.org/10.1017/jfm.2015.475

[9] Pröbsting, S., Yarusevych, S. "Laminar separation bubble development on an airfoil emitting tonal noise", Journal of Fluid Mechanics, 780, pp. 167-191, 2015. https://doi.org/10.1017/jfm.2015.427
[10] Boutilier, M. S. H., Yarusevych, S. "Separated shear layer transition over an airfoil at a low Reynolds number", Physics of Fluids, 24(8), Article Number: 084105, 2012.

https://doi.org/10.1063/1.4744989

[11] Kirk, T. M., Yarusevych, S. "Vortex shedding within laminar separation bubbles forming over an airfoil", Experiments in Fluids, 58(5), Article Number: 43, 2017. https://doi.org/10.1007/s00348-017-2308-Z

[12] Fujiwara, G., Sunada, Y., Rinoie, K. "Vortex Shedding from Laminar Separation Bubble Undergoing Oscillating Behavior near Airfoil Stall", In: 2018 AIAA Aerospace Science Meeting, Kissimmee, FL, USA, 2018, Article Number: 1084.

https://doi.org/10.2514/6.2018-1084

[13] Paterson, R. W., Vogt, P. G., Fink, M. R., Munch, C. L. "Vortex Noise of Isolated Airfoils", Journal of Aircraft, 10(5), pp. 296-302, 1973. https://doi.org/10.2514/3.60229

[14] Arbey, H., Bataille, J. "Noise generated by airfoil profiles placed in a uniform laminar flow", Journal of Fluid Mechanics, 134, pp. 33-47, 1983.

https://doi.org/10.1017/S0022112083003201

[15] Chong, T. P., Joseph, P. "'Ladder" structure in tonal noise generated by laminar flow around an airfoil", The Journal of the Acoustical Society of America, 131(6), Article Number: EL461, 2012. https://doi.org/10.1121/1.4710952

[16] Nash, E. C., Lowson, M. V., McAlpine, A. "Boundary-layer instability noise on aerofoils", Journal of Fluid Mechanics, 382, pp. 27-61, 1999. https://doi.org/10.1017/S002211209800367X

[17] Yarusevych, S., Boutilier, M. S. H. "Vortex Shedding of an Airfoil at Low Reynolds Numbers", AIAA Journal, 49(10), pp. 2221-2227, 2011. https://doi.org/10.2514/1.J051028

[18] Balla, E., Vad, J. "A Semi-Empirical Model for Predicting the Frequency of Profile Vortex Shedding Relevant to Low-Speed Axial Fan Blade Sections", In: Proceedings of 13th European Conference on Turbomachinery Fluid dynamics \& Thermodynamics, Lausanne, Switzerland, 2019, Article ID: ETC2019-311. 
[19] Daku, G., Vad, J. "Experiment-based preliminary design guidelines for consideration of profile vortex shedding flow low-speed axial fan blades", In: Proceedings of ASME Turbo Expo 2020: Turbomachinery Technical Conference and Exposition (GT2020), London, England, 2020, Article ID: GT2020-14214.

[20] Walters, D. K., Cokljat, D. "A Three-Equation Eddy-Viscosity Model for Reynolds-Sveraged Navier-Stokes Simulations of Transitional Flow", Journal of Fluids Engineering, 130(12), Article Number: 121401, 2008.

https://doi.org/10.1115/1.2979230

[21] Langtry, R. B., Menter, F. R. "Correlation-Based Transition Modeling for Unstructured Parallelized Computational Fluid Dynamics Codes", AIAA Journal, 47(12), pp. 2894-2906, 2009. https://doi.org/10.2514/1.42362
[22] De Gennaro, M., Kühnelt, H., Zanon, A. "Numerical Prediction of the Tonal Airborne Noise for NACA 0012 Aerofoil at Moderate Reynolds Number Using a Transitional URANS Approach", Archives of Acoustics, 42(4), pp. 653-675, 2017. https://doi.org/10.1515/aoa-2017-0069

[23] Novak, L., Bajcar, T., Širok, B., Orbanić, A., Bizjan, B. "Investigation of vortex shedding from an airfoil by computational fluid dynamic simulation and computer-aided flow visualization", Thermal Science, 22(6), pp. 3023-3033, 2018. https://doi.org/10.2298/TSC1170615002N

[24] Ffowcs Williams, J. E., Hawkings, D. L. "Sound Generated by Turbulence and Surfaces in Arbitrary Motion", Philosophical Transactions of the Royal Society: Series A, Mathematical and Physical Sciences, 264(1151), pp. 321-342, 1969.

\section{Appendix}

Table 1 Results of all simulation and BPM, $\operatorname{Re}_{C}=50000$ estimation, * multiple peaks; $\uparrow$ noisy, hard to determine peak; $\ddagger$ noisy, impossible to determine peak. The percentage value in the instability occurrence column represents the instability origin point with respect to the chord length from the leading edge

\begin{tabular}{|c|c|c|c|c|c|c|c|c|c|}
\hline \multirow[b]{2}{*}{$\begin{array}{l}\text { AoA } \\
{\left[{ }^{\circ}\right]}\end{array}$} & \multirow[b]{2}{*}{ model } & \multicolumn{2}{|c|}{$\infty$ spacing } & \multicolumn{2}{|c|}{$0.5 \cdot c$ spacing } & \multicolumn{2}{|c|}{$0.5 \cdot c$ spacing } & \multicolumn{2}{|r|}{$0.5 \cdot c$ spacing } \\
\hline & & $\begin{array}{l}f_{\text {peak }} \\
{[\mathrm{Hz}]}\end{array}$ & $\begin{array}{l}\text { instability } \\
\text { occurrence, flow } \\
\text { phenomenon }\end{array}$ & $\begin{array}{l}f_{\text {peak }} \\
{[\mathrm{Hz}]}\end{array}$ & $\begin{array}{c}\text { instability } \\
\text { occurrence, flow } \\
\text { phenomenon }\end{array}$ & $\begin{array}{l}f_{\text {peak }} \\
{[\mathrm{Hz}]}\end{array}$ & $\begin{array}{c}\text { instability } \\
\text { occurrence, flow } \\
\text { phenomenon }\end{array}$ & $\begin{array}{l}f_{\text {peak }} \\
{[\mathrm{Hz}]}\end{array}$ & $\begin{array}{l}\text { instability } \\
\text { occurrence, flow } \\
\text { phenomenon }\end{array}$ \\
\hline \multirow[t]{3}{*}{0} & SST & 1500 & in the wake & 1200 & in the wake & 1300 & in the wake & 850 & $\begin{array}{c}\text { suction and pressure } \\
\text { side } 80 \%\end{array}$ \\
\hline & $k-k l-\omega$ & 1500 & in the wake & 1200 & in the wake & 1200 & in the wake & 1700 & $\begin{array}{c}\text { suction and pressure } \\
\text { side } 85 \%\end{array}$ \\
\hline & BPM & 1000 & LBL & & & & & & \\
\hline \multirow[t]{3}{*}{2} & SST & 1000 & suction side $80 \%$ & 1200 & suction side $80 \%$ & 1050 & in the wake & 880 & $\begin{array}{l}\text { suction side } 80 \% \\
\text { pressure side } 90 \%\end{array}$ \\
\hline & $k-k l-\omega$ & 1150 & suction side $75 \%$ & 1200 & suction side $80 \%$ & 1000 & in the wake & 1700 & $\begin{array}{c}\text { suction and pressure } \\
\text { side } 80 \%\end{array}$ \\
\hline & BPM & no peak & & & & & & & \\
\hline \multirow[t]{3}{*}{4} & SST & $700^{*}$ & $\begin{array}{l}\text { separation } \\
\text { dominates }\end{array}$ & 1050 & suction side $70 \%$ & 1050 & suction side $80 \%$ & 850 & $\begin{array}{l}\text { suction side } 80 \% \\
\text { pressure side } 90 \%\end{array}$ \\
\hline & $k-k l-\omega$ & $\begin{array}{c}350^{*} \\
\text { and } \\
1600\end{array}$ & $\begin{array}{l}\text { separation } \\
\text { dominates }\end{array}$ & 1000 & suction side $70 \%$ & 1000 & suction side $80 \%$ & 1700 & $\begin{array}{c}\text { suction and pressure } \\
\text { side } 80 \%\end{array}$ \\
\hline & BPM & 1600 & separation & & & & & & \\
\hline 5.6 & SST & 1800 & $\begin{array}{l}\text { separation noise } \\
\text { only }\end{array}$ & 800 & suction side $70 \%$ & 1050 & suction side $70 \%$ & 850 & $\begin{array}{l}\text { suction side } 75 \% \\
\text { pressure side } 90 \%\end{array}$ \\
\hline \multirow[t]{2}{*}{6} & $k-k l-\omega$ & 900 & $\begin{array}{l}\text { separation noise } \\
\text { only }\end{array}$ & 1200 & suction side $65 \%$ & 1000 & suction side $80 \%$ & 1700 & $\begin{array}{c}\text { suction and pressure } \\
\text { side } 80 \%\end{array}$ \\
\hline & ВРМ & 1600 & separation & & & & & & \\
\hline
\end{tabular}


Table 2 Results of all simulation and BPM, $\operatorname{Re}_{C}=125000$ estimation, * multiple peaks; $\dagger$ noisy, hard to determine peak; $\$$ noisy, impossible to determine peak. The percentage value in the instability occurrence column represents the instability origin point with respect to the chord length from the leading edge

\begin{tabular}{|c|c|c|c|c|c|c|c|c|c|}
\hline \multirow[b]{2}{*}{$\begin{array}{l}\text { AoA } \\
{\left[^{\circ}\right]}\end{array}$} & \multirow[b]{2}{*}{ model } & \multicolumn{2}{|r|}{$\infty$ spacing } & \multicolumn{2}{|c|}{$0.5 \cdot c$ spacing } & \multicolumn{2}{|c|}{$0.5 \cdot c$ spacing } & \multicolumn{2}{|r|}{$0.5 \cdot c$ spacing } \\
\hline & & $\begin{array}{l}f_{\text {peak }} \\
{[\mathrm{Hz}]}\end{array}$ & $\begin{array}{l}\text { instability } \\
\text { occurrence, flow } \\
\text { phenomenon }\end{array}$ & $\begin{array}{l}f_{\text {peak }} \\
{[\mathrm{Hz}]}\end{array}$ & $\begin{array}{l}\text { instability } \\
\text { occurrence, flow } \\
\text { phenomenon }\end{array}$ & $\begin{array}{l}f_{\text {peak }} \\
{[\mathrm{Hz}]}\end{array}$ & $\begin{array}{l}\text { instability } \\
\text { occurrence, flow } \\
\text { phenomenon }\end{array}$ & $\begin{array}{l}f_{\text {peak }} \\
{[\mathrm{Hz}]}\end{array}$ & $\begin{array}{l}\text { instability } \\
\text { occurrence, flow } \\
\text { phenomenon }\end{array}$ \\
\hline \multirow[t]{2}{*}{0} & SST & 2500 & $\begin{array}{c}\text { suction and } \\
\text { pressure side } 80 \%\end{array}$ & 3300 & $\begin{array}{c}\text { suction and } \\
\text { pressure side } 75 \%\end{array}$ & $3900 *$ & $\begin{array}{c}\text { suction and } \\
\text { pressure side } 80 \%\end{array}$ & $2700^{*}$ & $\begin{array}{c}\text { suction and pressure } \\
\text { side } 70 \%\end{array}$ \\
\hline & BPM & 3100 & LBL & & & & & & \\
\hline \multirow[t]{2}{*}{2} & SST & $2300 *$ & $\begin{array}{c}\text { suction side } 70 \% \\
\text { pressure side } 95 \%\end{array}$ & $3300^{*}$ & $\begin{array}{c}\text { suction side } 65 \% \\
\text { pressure side } 80 \%\end{array}$ & $3900 *$ & $\begin{array}{c}\text { suction and } \\
\text { pressure side } 80 \%\end{array}$ & $2400 *$ & $\begin{array}{c}\text { suction and pressure } \\
\text { side } 70 \%\end{array}$ \\
\hline & BPM & 3100 & LBL & & & & & & \\
\hline \multirow[t]{2}{*}{4} & SST & 2300 & suction side $45 \%$ & $3800^{*}$ & $\begin{array}{c}\text { suction side } 65 \% \\
\text { pressure side } 80 \%\end{array}$ & $3900^{+}$ & $\begin{array}{c}\text { suction side } 70 \% \\
\text { pressure side } 85 \%\end{array}$ & $2100 *$ & $\begin{array}{l}\text { suction side } 60 \% \\
\text { pressure side } 70 \%\end{array}$ \\
\hline & BPM & 4000 & LBL & & & & & & \\
\hline \multirow[t]{2}{*}{5.6} & SST & 2100 & $\begin{array}{l}\text { separation noise } \\
\text { only }\end{array}$ & 3800 & $\begin{array}{c}\text { suction side } 55 \% \\
\text { pressure side } 90 \%\end{array}$ & $3900^{+}$ & $\begin{array}{c}\text { suction side } 65 \% \\
\text { pressure side } 80 \%\end{array}$ & $2000 *+$ & $\begin{array}{l}\text { suction side } 60 \% \\
\text { pressure side } 65 \%\end{array}$ \\
\hline & BPM & 3100 & separation & & & & & & \\
\hline
\end{tabular}

Table 3 Results of all simulation and BPM, $\operatorname{Re}_{\mathrm{C}}=200000$ estimation, ${ }^{*}$ multiple peaks; $\uparrow$ noisy, hard to determine peak; $¥$ noisy, impossible to determine peak. The percentage value in the instability occurrence column represents the instability origin point with respect to the chord length from the leading edge

\begin{tabular}{|c|c|c|c|c|c|c|c|c|c|}
\hline \multirow[b]{2}{*}{$\begin{array}{l}\text { AoA } \\
{\left[{ }^{\circ}\right]}\end{array}$} & \multirow[b]{2}{*}{ model } & \multicolumn{2}{|c|}{$\infty$ spacing } & \multicolumn{2}{|c|}{$0.5 \cdot c$ spacing } & \multicolumn{2}{|c|}{$0.5 \cdot c$ spacing } & \multicolumn{2}{|c|}{$0.5 \cdot c$ spacing } \\
\hline & & $\begin{array}{l}f_{\text {peak }} \\
{[\mathrm{Hz}]}\end{array}$ & $\begin{array}{l}\text { instability } \\
\text { occurrence, flow } \\
\text { phenomenon }\end{array}$ & $\begin{array}{l}f_{\text {peak }} \\
{[\mathrm{Hz}]}\end{array}$ & $\begin{array}{l}\text { instability } \\
\text { occurrence, flow } \\
\text { phenomenon }\end{array}$ & $\begin{array}{l}f_{\text {peak }} \\
{[\mathrm{Hz}]}\end{array}$ & $\begin{array}{l}\text { instability } \\
\text { occurrence, flow } \\
\text { phenomenon }\end{array}$ & $\begin{array}{l}f_{\text {peak }} \\
{[\mathrm{Hz}]}\end{array}$ & $\begin{array}{l}\text { instability } \\
\text { occurrence, flow } \\
\text { phenomenon }\end{array}$ \\
\hline \multirow[t]{3}{*}{0} & SST & 3000 & $\begin{array}{l}\text { suction and } \\
\text { pressure side } 80 \%\end{array}$ & 5800 & $\begin{array}{l}\text { suction and } \\
\text { pressure side } 70 \%\end{array}$ & 6000 & $\begin{array}{l}\text { suction and } \\
\text { pressure side } 70 \%\end{array}$ & $5000^{+}$ & $\begin{array}{l}\text { suction and pressure } \\
\text { side } 65 \%\end{array}$ \\
\hline & $k-k l-\omega$ & 4000 & $\begin{array}{l}\text { suction and } \\
\text { pressure side } 75 \%\end{array}$ & 5700 & $\begin{array}{l}\text { suction and } \\
\text { pressure side } 75 \%\end{array}$ & 1000 & in the wake & $1500 *+$ & $\begin{array}{l}\text { suction and pressure } \\
\text { side } 65 \%\end{array}$ \\
\hline & BPM & 6500 & LBL & & & & & & \\
\hline \multirow[t]{3}{*}{2} & SST & 5200 & $\begin{array}{l}\text { suction side } 65 \% \\
\text { pressure side } 90 \%\end{array}$ & 5800 & $\begin{array}{l}\text { suction side } 60 \% \\
\text { pressure side } 75 \%\end{array}$ & 5600 & $\begin{array}{l}\text { suction side } 70 \% \\
\text { pressure side } 75 \%\end{array}$ & 4700 & $\begin{array}{l}\text { suction side } 60 \% \\
\text { pressure side } 65 \%\end{array}$ \\
\hline & $k-k l-\omega$ & 5200 & $\begin{array}{l}\text { suction side } 60 \% \\
\text { pressure side } 90 \%\end{array}$ & 5800 & $\begin{array}{l}\text { suction side } 65 \% \\
\text { pressure side } 70 \%\end{array}$ & 5600 & $\begin{array}{l}\text { suction side } 65 \% \\
\text { pressure side } 85 \%\end{array}$ & 1200 & $\begin{array}{l}\text { suction and pressure } \\
\text { side } 65 \%\end{array}$ \\
\hline & BPM & 6500 & LBL & & & & & & \\
\hline \multirow[t]{3}{*}{4} & SST & 4000 & suction side $40 \%$ & 5300 & $\begin{array}{l}\text { suction side } 55 \% \\
\text { pressure side } 80 \%\end{array}$ & $\ddagger$ & $\begin{array}{l}\text { suction side } 65 \% \\
\text { pressure side } 80 \%\end{array}$ & 3100 & $\begin{array}{l}\text { suction side } 60 \% \\
\text { pressure side } 65 \%\end{array}$ \\
\hline & $k-k l-\omega$ & 4000 & suction side $40 \%$ & 5400 & $\begin{array}{l}\text { suction side } 60 \% \\
\text { pressure side } 80 \%\end{array}$ & 5600 & $\begin{array}{l}\text { suction side } 70 \% \\
\text { pressure side } 85 \%\end{array}$ & 3100 & $\begin{array}{l}\text { suction and pressure } \\
\text { side } 65 \%\end{array}$ \\
\hline & BPM & 6500 & separation & & & & & & \\
\hline 5.6 & SST & 7000 & separation noise & 5450 & $\begin{array}{l}\text { suction side } 55 \% \\
\text { pressure side } 80 \%\end{array}$ & 5500 & $\begin{array}{l}\text { suction side } 60 \% \\
\text { pressure side } 85 \%\end{array}$ & 4300 & $\begin{array}{l}\text { suction side } 60 \% \\
\text { pressure side } 65 \%\end{array}$ \\
\hline \multirow[t]{2}{*}{6} & $k-k l-\omega$ & 8000 & separation noise & 5500 & $\begin{array}{l}\text { suction side } 50 \% \\
\text { pressure side } 95 \%\end{array}$ & 6800 & $\begin{array}{l}\text { suction side } 60 \% \\
\text { pressure side } 90 \%\end{array}$ & $\neq$ & $\begin{array}{l}\text { suction and pressure } \\
\text { side } 65 \%\end{array}$ \\
\hline & BPM & 5000 & separation & & & & & & \\
\hline
\end{tabular}

